\title{
A Longitudinal Field Investigation of Gender Differences in Individual Technology Adoption Decision-Making Processes
}

\author{
Viswanath Venkatesh \\ University of Maryland, College Park \\ Michael G. Morris \\ Air Force Institute of Technology \\ and \\ Phillip L. Ackerman \\ Georgia Institute of Technology
}

\begin{abstract}
This research investigated gender differences in the overlooked context of individual adoption and sustained usage of technology in the workplace using the theory of planned behavior (TPB ). User reactions and technology usage behavior were studied over a 5-month period among 355 workers being introduced to a new software technology application. When compared to women's decisions, the decisions of men were more strongly influenced by their attitude toward using the new technology. In contrast, women were more strongly influenced by subjective norm and perceived behavioral control. Sustained technology usage behavior was driven by early usage behavior, thus fortifying the lasting influence of gender-based early evaluations of the new technology. These findings were robust across income, organization position, education, and computer self-efficacy levels. $\odot 2000$ Academic Press
\end{abstract}

We thank Susan Brown (Indiana University), Fred Davis (University of Arkansas), Cheri Speier (Michigan State University), and Tracy Ann Sykes (University of Maryland) for their many comments and suggestions on earlier versions of the paper. We also thank Tracy for her help in improving the readability of the paper and copy-editing.

Address correspondence and reprint requests to: Professor Viswanath Venkatesh, Robert H. Smith School of Business, University of Maryland, College Park, Maryland 20742. E-mail: vvenkate@rhsmith.umd.edu. 
Organizational investments in information technologies (IT) have increased significantly in the past decade. These investments specifically aim to increase individual productivity and thus contribute to organizational productivity. While advances in technology continue at an astronomical pace, the use of these emerging information technologies has fallen well below expectations (J ohansen \& Swigart, 1996; Moore, 1991; Norman, 1993; Weiner, 1993) and has been identified as one of the plausible explanations for productivity gains from IT investments being less than expected (Landauer, 1995; Sichel, 1997). Clearly, understanding the factors influencing user acceptance, adoption, and usage of emerging information technologies in the workplace is a critical issue for researchers and practitioners.

This research aims to deepen our understanding of the underlying phenomena of technology adoption and usage decisions by focusing on differences in the decision-making processes of men and women. Given the extensive role of technol ogy in businesses and the increasing presence of women in professional domains (e.g., Minton \& Schneider, 1980), understanding gender differences in individual technology adoption and usage decisions is an important issue for organizational psychologists as they attempt to manage the organizational change process. In understanding gender, it is important to recognize that there are at least two commonly understood definitions of gender in psychology-the first is consistent with biological sex while the second views gender as more of a psychol ogical construct (see Bem, 1981). Given the lack of research into gender differences in decision making regarding technology, we begin attacking the problem with gender defined as biological sex. Much of the large body of research on gender differences has examined mean differences between women and men in terms of abilities, traits, and psychological constructs (see Minton \& Schneider, 1980 for a review). There has also been research focusing on gender differences in decision-making processes (e.g., Barnett $\&$ Karson, 1989; Crow, Fok, Hartman, \& Payne, 1991; Eccles, 1987; Tashakkori \& Thompson, 1991); however, little, if any, previous research has examined gender differences in the salience of different determinants of adoption and sustained usage of technology.

In studying acceptance and use of a technology, it is important to examine the phenomenon over a duration of time with increasing user experience with the specific system (e.g., Davis, Bagozzi, \& Warshaw, 1989) rather than just a cross-sectional snapshot. In the earliest stages of technol ogy introduction, users aremaking an "acceptance" decision, which has been shown to besystematically different from "sustained usage" decisions as user experience increases (e.g., Davis et al., 1989). Therefore, to help gain a thorough understanding of the underlying phenomena, this research studies the role of gender in initial technology acceptance decisions and usage decisions. Researchers have studied technol ogy acceptance and usage from different perspectives using theoretical models from psychology. Among the different theoretical models, the theory of planned behavior (TPB) is very well suited to further our understanding of technol ogy acceptance and usage behavior due to its strong theoretical anchors and extensive applicability across a wide range of behaviors (see Ajzen, 1985, 
1991), including technol ogy adoption and usage (e.g., Mathieson, 1991; Taylor \& Todd, 1995). We conducted a longitudinal field investigation of gender differences in the relative influence of attitude toward using technology, subjective norm, and perceived behavioral control in determining individual adoption and sustained usage of a new software system in the workplace.

\section{GENDER DIFFERENCES IN INDIVIDUAL DECISION-MAKING ABOUT TECHNOLOGY}

The theoretical framework employed in this research to understand individual adoption and usage of technology is the theory of planned behavior (Ajzen, 1985, 1991). TPB defines relationships among beliefs, attitude toward a behavior (A), subjective norm (SN), perceived behavioral control (PBC), behavioral intention ( $\mathrm{BI}$ ), and behavior (B). The following two equations hel $\mathrm{p}$ capture the essence of predicting intention and behavior:

$$
\begin{aligned}
& \mathrm{BI} \cong \mathrm{A}+\mathrm{SN}+\mathrm{PBC} \\
& \mathrm{B} \cong \mathrm{BI}+\mathrm{PBC}^{1} .
\end{aligned}
$$

TPB has been widely applied across a range of disciplines such as marketingconsumer behavior (Berger, 1993), leisure behavior (Ajzen \& Driver, 1992), and medicine (Randall \& Gibson, 1991). TPB has also been applied in technology adoption and usage contexts to explain an individual's adoption of new technologies (e.g., Harrison, Mykytyn, \& Riemenschneider, 1997; Mathieson, 1991; Taylor \& Todd, 1995). In understanding how gender differences will play out in technology adoption and usage decisions, it is important to first understand the underlying mechanisms influencing A, SN, and PBC: (a) attitude toward using technol ogy is determined by perceptions of usefulness (e.g., Davis et al., 1989; Mathieson, 1991; Taylor \& Todd, 1995), (b) subjective norm is influenced by peer influence and superior's influence (e.g., Taylor \& Todd, 1995), and (c) perceived behavioral control is influenced by self-efficacy (Taylor \& Todd, 1995). This paper builds on previous studies of TPB and turns its focus to the role gender may play in technology adoption decisions.

J ust as a significant body of evidence suggests there are mean differences between women and men across a variety of domains, the evidence of gender differences in decision-making processes also encompasses a breadth of contexts. For example, studies have reported decision processing differences between women and men in college course and major selection (Gianakos \& Subich, 1988; Wilson, Stocking, \& Goldstein, 1994), retirement decisions (Talaga \& Beehr, 1995), financial decision making (Powell \& Ansic, 1997), and

${ }^{1}$ Although behavioral control issues were initially associated with actual control (Ajzen, 1985), in more recent work (Ajzen, 1991), it has been acknowledged that of "greater psychol ogical interest than actual control, however, is the perception of behavioral control and its impact on intentions and actions" (p. 185). 
hospital problem solving (Steffen \& Nystrom, 1988). Similarly, other researchers have reported gender differences in what is perceived or processed as being "ethical" (e.g., Dawson, 1995; Franke, Crown, and Spake, 1997; Galbraith \& Stephenson, 1993). In another notable study, Tashakkori (1993) found evidence to suggest that the attributes important in determining self-esteem for women and men are different. Often such attributes are manifest as schemas used to process information. Schematic processing suggests that information is encoded and processed consistent with a specific cognitive structure that organizes and directs an individual's perceptions (Bem, 1981). As a result, in the decisionmaking process, perceptions and actions typically tend to reflect the biases created by specific schemas (e.g., Nisbett \& Ross, 1980). Thus, gender schema aretypically viewed as a prescriptivestandard or guide (Kagan, 1964; Kohl berg, 1966), causing an unconscious or internalized direction of activity consistent with theschema. Sex typing may help identify attributes and behaviors salient to women and men, respectively (cf. Bem \& Allen, 1974).

The current research aims to study gender differences in technology adoption and usage. Thus, in effect, the current work examines the role of gender as a moderator of key TPB relationships and how usage decisions are made over time with increasing user experience with the specific technology. Figure 1 presents TPB and the proposed role of gender as a moderator over time.

\section{Attitude toward Behavior}

Attitude toward a behavior (A) "refers to the degree to which a person has a favorable or unfavorable evaluation or appraisal of the behavior in question" (Ajzen, 1991, p. 188). An individual's attitude toward a behavior is determined by beliefs about the consequences of the behavior and the individual's evaluation of the consequences. There is substantial evidence in organizational behavior and management information systems research (e.g., Davis, 1989; Davis, et al., 1989; Mathieson, 1991; Taylor \& Todd, 1995) suggesting that the key underlying cognition determining an individual's attitude toward the behavior of adopting and using a new technol ogy in the workplaceis his or her perceptions about theusefulness of thetechnology (i.e., the extent to which a person believes

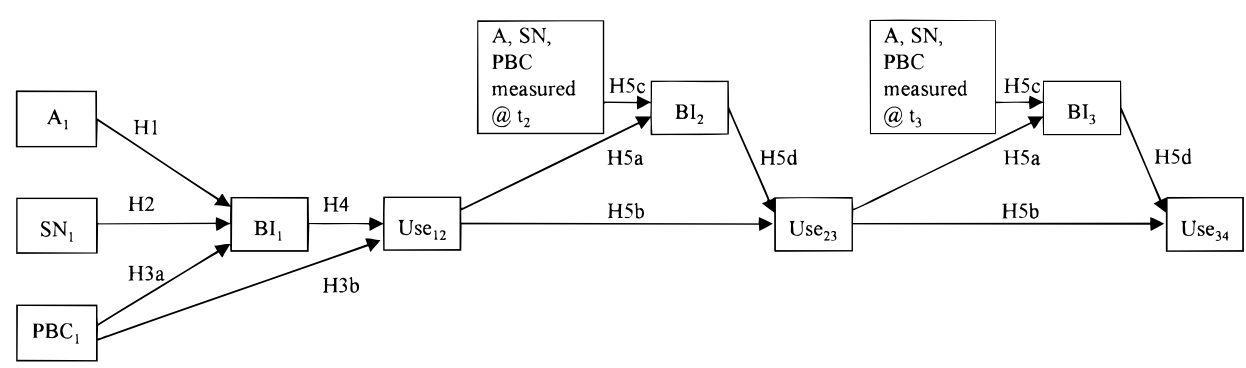


that using a particular technology will enhance his or her job performance). Specifically, the link between usefulness perceptions and attitudetoward using a new technology has been shown to have path coefficients ranging from .50 (Davis et al., 1989) to.79 (Taylor \& Todd, 1995). Given these strong results, one can conclude that even though attitude is an affective reaction, ${ }^{2}$ an individual's attitude toward using a technology in the workplace reflects instrumentality and extrinsic motivation to use technology.

Prior research provides a basis to expect gender differences in the salience of instrumentality in decision-making processes about a new system. Research on gender differences has suggested that for men, work is typically the most salient role, while the family role is perceived to be less important (e.g., Barnett \& Marshall, 1991). Similarly, O'N eil (1982) suggested that men are greatly preoccupied with work, accomplishments, and eminence. Furthermore, men, more so than women, are motivated by achievement needs (Hoffman, 1972). Others state that men adopt strategies focused on bottom-line results vs methods used to achieve those results (Hennig \& J ardim, 1977). Men, therefore, tend to be more directed toward impersonal and individualistic tasks and goals, compared to women (Baird, 1976; Carlson, 1971; Gill, Stockard, J ohnson, and Williams, 1987; Rotter \& Portugal, 1969; see also Stein \& Bailey, 1973). Others have also reported such differences. For example, Rosenkrantz, Vogel, Bee, Broverman, and Broverman (1968) suggested that "objective" and "logical" are more male-valued traits. Men tend to exhibit more of such "masculine" traits (e.g., assertive), as identified by different inventories including Bem's Sex Role Inventory (BSRI; Bem, 1981), compared to women. There is also meta-analytic evidence (cf. Taylor \& Hall, 1982) to suggest that masculine scales correlate with instrumental behaviors. "Dominance" is another label used for masculine traits (e.g., Deaux, 1985), while Skitka and Maslach (1996) use the term "agency" to describe the same concept, and Minton and Schneider (1980) concluded that men may be more task-oriented than women. Such a view is consistent with Sargent's (1981) contention that men have been socialized to value having an impact and, therefore, tend to engage in task-oriented or instrumental behavior. Thus, we expect that an individual's initial attitude toward using a technology, which reflects instrumental outcomes related to technology use, will be more salient to men than women, and this is reflected in our first hypothesis:

H1: As a determinant of behavioral intention to use a system, attitude toward using the system will influence men more strongly than it will influence women.

\footnotetext{
2 There is, admittedly, some disagreement on this point. For example, some argue that attitudes are evaluations of some target which someone may never have experienced, reacted to, or felt affect toward. While not entirely a "cold cognition," it is a holistic judgment about a target that incorporates a variety of thetarget's perceived features. These points are courtesy of an anonymous reviewer, whom we thank for illuminating this important distinction.
} 
Subjective Norm

Subjective norm (SN) "refers to the perceived social pressure to perform or not to perform the behavior" (Ajzen, 1991, p. 188). In the context of technology usage, thekey factors underlying subjectivenorm are peer influenceand superior's influence (Mathieson, 1991; Taylor \& Todd, 1995). Although the use of the technologies (being introduced in the organizations studied in this research) was voluntary, in organizational settings, the normative pressure from superiors and peers during the early stages of behavior is expected to weigh heavily on individual intent. Such a direct link between subjective norm and intention can be explained as "compliance," where an individual accepts influence in order to gain a favorable reaction from another person or group (Kelman, 1958; Warshaw 1980; Venkatesh \& Davis, 2000). Therefore, we expect the extent of gender differences in the role of subjective norm will be tied to the extent to which women and men are influenceable and respond to informational input from others.

Research has shown that women exhibit more "feminine" traits (e.g., tenderness), as identified by BSRI (Bem, 1981), compared to men. Also, the metaanalysis of Taylor and Hall (1982) suggested that these femininetraits correlate with "expressive" behaviors. Many studies have suggested that as a result of socialization pressures, the feminine personality emerges in terms of communion with others (Chodorow, 1974) and, as a result, women see relationships as more important in their lives than men do (Erikson, 1968; Hodgson \& Watson, 1987; Kanter, 1977, 1987; Miller, 1976). Women appear to be more strongly motivated by affiliation needs (H offman, 1972; Kohlberg \& Kramer, 1969) and tend to express a higher degree of interest in person-oriented professions (Weller, Shlomi, \& Zimont, 1976). Gill et al. (1987) suggest that women, more than men, are oriented toward interpersonal goals and achievement in interpersonal relationships (see also, Carlson, 1971; Gilligan, 1982; Stein \& Bailey, 1973). Similarly, Rosenkrantz et al. (1968) suggested that an awareness of others' feelings is a trait exhibited more strongly by women than men. Consistent with this line of research, Skitka and Maslach (1996) found that female participants used "communion" constructs (defined as concern for the harmonious functioning of the group, interdependence, and concern with relationships in general) in the process of describing others. Furthermore, research has suggested that women may be more likely to retain nonproductive employees for social reasons, whereas men are more likely to terminate nonproductive employees (Barnett \& Karson, 1989; Landau \& Leventhal, 1976).

There are also gender differences in influenceability (Becker, 1986; Eagly \& Carli, 1981). A comparison of women and men, in terms of compliance, indicated that women are more likely to comply with orders, whereas men are more likely to rebel (e.g., Minton, Kagan, \& Levine, 1971; Stockard, Van-de-Kragt, \& Dodge, 1988). Similar research suggests that women aremore likely to conform with a majority opinion (Eagly, 1978; Maccoby \& J acklin, 1974) and may even internalize subordination to be part of their personality (e.g., Crawford, Chaffin, \& Fitton, 1995). Related research suggests that women also tend to 
be more concerned (than men) with pleasing others (e.g., Miller, 1976). Based on a review of research, Minton and Schneider (1980) concluded men are somewhat more self-confident and independent than women, who are more people-oriented.

Another significant body of research suggests similar outcomes, but on the basis of a different causal mechanism. There is evidence to suggest that, on average, women pay more attention to social cues and men pay more attention to nonsocial cues such as objects and visual patterns (e.g., Garai \& Scheinfeld, 1968; Parsons \& Bales, 1955; Williams \& Best, 1982). Roberts (1991), based on a review of research in the area, suggested that both women and men are equally attentive and capable of processing social cues, but that gender differences surface in the extent to which they yield to such cues, with women yiel ding more to such cues. Roberts (1991) goes on to explain that these differences vary substantively by suggesting that women are more responsive to the information and feedback received from others. Specifically, Roberts (1991) identified the bases for women's higher levels of responsiveness to others' evaluations: while men adopt a competitive attitude and thus, a self-confident (and potentially, overconfident) approach (see Lundeberg, Fox, \& Puncochar, 1994), women value informational inputs more and view such situations as potential opportunities to learn more about their abilities. Barnett and Karson (1989) summarized this line of research by concluding that women are likely to select actions in terms that are likely to be approved by others as opposed to following rules or principles that are separate from relationships. This implies that during the initial stages of technology adoption (i.e., shortly after being introduced to a technology), women will be more sensitive to others' informational input about a new technology and factor such information in their decision making to a greater extent than men. We expect that these differences will result in a greater deference to others' opinions among women (when compared to men) in the process of decision making about the new technology in the workplace. Therefore,

$\mathrm{H}$ 2: As a determinant of behavioral intention to use a system, subjective norm will influence women more strongly than it will influence men.

\section{Perceived Behavioral Control}

Perceived behavioral control (PBC) relates to the extent to which the person believes that he or she has control over personal or external factors that may facilitate or constrain the behavioral performance (Ajzen, 1991). Consistent with this original definition of perceived behavioral control, prior research investigating technol ogy usage behavior has shown self-efficacy, resourcefacilitating conditions, and technology facilitating conditions to be determinants of the construct (Taylor \& Todd, 1995). More recent TPB research (e.g., Sparks, Guthrie, \& Shepherd, 1997) has refined and focused our thinking with evidence showing that perceived difficulty is the most important component of perceived behavioral control. This is consistent with Ajzen's (1991) definition of perceived behavioral control: “. . . people's perception of theease or difficulty of performing 
the behavior of interest" (p. 183). Thus, in understanding gender differences in technol ogy adoption, we focus on perceptions of ease and/or difficulty. In the context of technology adoption and usage in the workplace, there is evidence to suggest that the availability of support staff is an organizational response to hel p users overcome barriers and hurdles to technol ogy use, especially during the early stages of learning and use (e.g., Bergeron, Rivard, \& De Serre, 1990). In fact, consultant support has been conceptually and empirically shown to influence perceptions of behavioral control (Cragg \& King, 1993; Harrison et al., 1997).

The research base discussed in understanding gender differences in attitude toward using technol ogy also hel ps us understand potential gender differences in the salience of perceived behavioral control. Wereviewed research supporting the higher level of importance of instrumentality for men, when compared to women. This higher level of salience of instrumentality to men is expected to have an impact on perceived behavioral control as well. Issues pertaining to constraints to behavior can be expected to recede into the background for those individuals for whom instrumentality is more salient (i.e., men), since their emphasis will be more on the outcome (instrumentality) rather than the process. That is, men are more likely to be willing to put in more effort to overcome constraints in order to achieve their objectives, without necessarily thinking about or emphasizing the magnitude of the effort involved. Women, on the other hand, tend to focus on the methods used to accomplish a task — suggesting a greater process orientation (Hennig \& J ardim, 1977; Rotter \& Portugal, 1969). Given the process-orientation of women and the lower levels of control generally perceived by women in the work environment, the perceived ease or difficulty of using technology is expected to have an important influence over their decisions to adopt (or reject) new technology in the workplace. Further, there is evidence to suggest that women display somewhat higher levels of computer anxiety (Bozionelos, 1996; Morrow, Presll, \& McElroy, 1986) and lower computer aptitude (Felter, 1985) compared to men (Chen, 1985). Both computer anxiety and computer aptitude have been related to perceptions of effort, thus suggesting that constraints to technol ogy use (perceived difficulty) will be more salient to women compared to men. Relevant to the business environment, previous research has suggested that women have lower levels of personal control with respect to their work (e.g., Mirowsky \& Ross, 1990; Ross \& Wright, 1998; Thoits, 1987). One possible explanation for such results is that women have been found to be particularly susceptible to learned helplessness_particularly in male-dominated contexts (Baucom, 1983; Baucom \& Danker-Brown, 1984). Therefore, in these contexts, constraints to technology usage (e.g., perceived difficulty in using the system) are expected to be particularly salient for women in their decisions to adopt or reject technology. This suggests that for initial technology adoption decisions, per TPB, the effect of perceived behavioral control on both intention and behavior (PBC-BI, PBCUSE) will be stronger for women as opposed to men. 
H3(a): As a determinant of behavioral intention to use a system, perceived behavioral control will influence women more than it will influence men.

H3(b): As a determinant of usage behavior, perceived behavioral control will influence women more than it will influence men.

\section{Behavioral Intention as a Determinant of Short-Term U sage}

In addition to perceived behavioral control, intention is expected to influence system usage. There is extensive evidence in psychology (see Ajzen, 1991 for a review; Ajzen \& Madden, 1986) supporting the role of intention as a predictor of behavior across a wide variety of domains. Based on a meta-analysis of 87 studies, Sheppard, Hartwick, and Warshaw (1988) found an intention- behavior correlation of 0.50 . Further, in information systems research, intention has been found to be a predictor of technology usage (e.g., Davis et al., 1989; Taylor \& Todd, 1995; Venkatesh \& Davis, 2000; Venkatesh \& Speier, 1999). We expect gender differences in the intention-usage behavior relationship as well. Even recent research has demonstrated such differences (e.g., Lu, 1999). Similarly, Van Roosmalen and McDaniel (1992) reported women, when compared to men, were more likely to sustain and follow up on expressed intents.

$\mathrm{H} 4$ : As a determinant of short-term usage behavior, intention will influence women more than it will influence men.

\section{Predicting Sustained Usage Behavior}

Prior research has demonstrated that past behavior is a key predictor of future behavior (Bagozzi \& Kimmel, 1995; Conner \& Armitage, 1998; N orman \& Smith, 1995). In addition, research has also shown that past behavior has a direct effect on future behavior that is not fully mediated by intention (e.g., Ajzen \& Madden, 1986; Bagozzi , 1981; Bentler \& Speckart, 1979). This relationship between past behavior and present-future behavior has been found both for habitual activities (e.g., cigarette smoking) and volitional activities (e.g., coupon usage) (Bagozzi, Baumgartner, \& Yi, 1992). The idea that direct experience with the behavior plays an important role in shaping future behavior is also supported by other work within the paradigm of attitude research (e.g., Fazio \& Zanna, 1978a, 1978b, 1981). Furthermore, other research (e.g., Szajna \& Scamell, 1993) suggests that to the degree that initial experiences with the new system create realistic expectations about future usage experiences, initial use of the system will play an important role in shaping future behavior (i.e., future usage) - even overriding subsequent perceptual and attitudinal input.

In fact, the importance of past behavior as a predictor of future behavior is consistent with recent meta-analytic research on the topic (Ouellette \& Wood, 1998). During the early stages of experience with the system, deliberated cognitions will play a critical role in shaping adoption decisions. However, with 
increasing experience of the particular behavior (i.e., system usage), subsequent behavior tends to be influenced more by automatic and quasi-automatic processes (Heckhausen \& Beckmann, 1990) than by conscious intention. In fact, in the case of habituated behaviors, based on a meta-analysis, Ouellette and Wood (1998) established that past behavior $(\beta=.45)$ was a stronger predictor of future behavior when compared to intention $(\beta=.27)$.

In predicting possible gender differences in the intention and behavior relationships, given the fact that women are more balanced and externally aware in the adoption and usage decisions (as outlined in $\mathrm{H} 2$ and $\mathrm{H} 3$ ), it is expected that past behavior may have less of an impact on future behavior than those less responsive to outside inputs. For those who tend to be less responsive to external influences (i.e., men), short-term usage behavior is likely to play a prominent role in intention formation and subsequent behavior.

H5(a): As a determinant of subsequent intention, prior usage behavior will influence men more than it will influence women.

$\mathrm{H} 5$ (b): As a determinant of sustained usage behavior, prior usage behavior will influence men more than it will influence women.

Similarly, the higher levels of awareness of external pressures among women is expected to cause slower habit formation and would also imply that even when formed, those habits will be of lower strength compared to habits of male counterparts. This process suggests that women's behavior will be more "considered" and less "automatic" than that of men. Thus, with increasing experience with the technology, deliberated cognitions will play a greater role in intention formation among women, and the resultant intentions will play more of a role in shaping their future behavior when compared to past behavior. ${ }^{3}$

$\mathrm{H} 5$ (c): As a determinant of subsequent intention, deliberated cognitions ( $A$, $\mathrm{SN}$, and $\mathrm{PBC}$ ) will influence women more than they will influence men.

$\mathrm{H}$ 5(d): As a determinant of sustained usage behavior, intention will influence women more than it will influence men.

\section{Method}

Participants

F our organizations participated in this study. The key criterion for inclusion was that a new technology application was being introduced in part or all of the organization. In each case, the use of the new technology was voluntary. A total of 420 individuals agreed to participate in the study. Three hundred fifty-five usable responses, including 160 women (45\%), were received to test TPB in the technology introduction context at all points of measurement. Eighty-six, 81, 89, and 99 individuals from each of the four sites respectively participated in the study. All participants had prior experience using computers-the average was six years with a range from six months to 18 years.

${ }^{3}$ We thank the second anonymous reviewer for insightful comments on this issue. 
None of the users had any prior knowledge about the specific software system being introduced.

\section{Procedure}

The specific software being introduced in each organization can be broadly categorized as an organization-wide system for data and information retrieval. All partici pants received a full-day training (six hours), which included a lecture for two hours, followed by two hours of interactivelecture (i.e., lecture combined with hands-on use), and two hours of hands-on use, with software consultants being available to hel $p$ during hands-on use. Multiple sessions of training were conducted in each organization with no more than 25 participants in each session. The authors did not participate in the training process to minimize biases, and the trainers and software consultants did not know about the research or its objectives. Centralized support staff from the organization that conducted the training was provided to help to participants who had questions or problems during the first week after training. Subsequent technical support was provided in-house.

While participation in the training was organizationally mandated, the use of the system in all participating organizations was voluntary. The survey was filled out manually without the use of any IT and tracked using a seating chart at the training sessions, bar codes on the instrument, and user login IDs. Follow-up questionnaires were mailed using the same bar codes totrack respondents over time. Participation in the initial and follow-up surveys was voluntary. The follow-up surveys were sent directly by the researchers to the respondents and mailed back to the researchers in prepaid envelopes. The consent form included the following sentences about the role of usage and anonymity of responses: "The records of this study will be kept private. In any sort of report we might publish or provide to your employer, we will not include any information that will make it possible to identify a subject. Results will always be presented in a summarized form. By signing this form, you also consent to allow us to track your system usage for a period not to exceed one year. In the case of usage also, the results will al ways be presented in a summarized form, thus protecting each individual subject's identity at all times."

User reactions to the technology were measured at three points in time: immediately after the initial training $\left(t_{1}\right)$, after one month of experience $\left(t_{2}\right)$, and after threemonths of experience $\left(t_{3}\right)$. Figure 2 presents a pictorial representation of the data collection effort. During the five-month period following the initial training, actual usage behavior was measured using system logs with $U_{S E_{12}}$ representing usage between $t_{1}$ and $t_{2}, U S E_{23}$ representing usage between $t_{2}$ and $t_{3}$, and $U S E_{34}$ representing usage between $t_{3}$ and five months postimplementation. While $t_{1}$ represented initial user reactions, $t_{2}$ and $t_{3}$ represented situations of significant direct experience with the behavior becoming more habituated. For the purpose of this research, we expected that analyzing user perceptions and behavior longitudinally allowed a detailed understanding of 


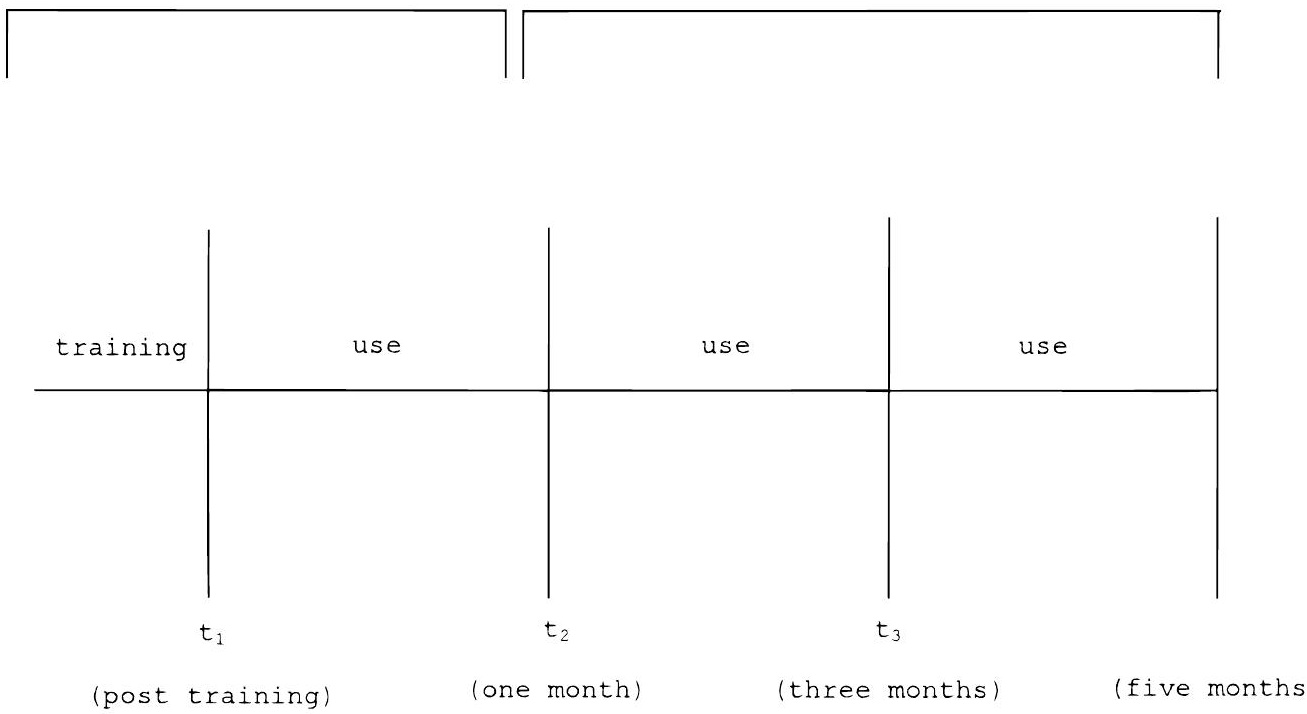

FIG. 2. Research design and timing of measurements.

gender differences in the technology adoption and usage decision-making processes. To that end, using each of the three points of measurement as a proxy for experience is consistent with prior research in the domain (e.g., Davis et al., 1989).

\section{Potential Confounding Factors}

There are several important demographic variables that could potentially confound gender differences in perceptions (for a discussion of these, see Lefkowitz, 1994). The typical procedure to handle such situations has been to statistically control for confounding variables. The most important covariates are those which upon inclusion eliminate gender differences (see Lefkowitz, 1994). Based on a careful analysis of a large sample ( $N=732$, including 361 women), Lefkowitz (1994) found that income was the most important covariate, and organization level was the second most important covariate and was more important than typically employed covariates. In addition, education level is an important covariate of gender. Specifically, men are overrepresented in categories of higher income, higher positions, and higher educational qualifications. Lefkowitz (1994) suggested that failing to control for the effect of such covariates may "underestimate the complexity of the issue under study" and yield results that "at worst, are misleading" (p. 341). Thus, in our research, weexamined the effect of these threekey potential confounds from prior organization behavior research: income, organization level, and education (see also Brenner, Blazini, \& Greenhaus, 1988; Gould \& Werbel, 1983; Sauser \& York, 1978; Schuler, 1975). In addition, in the context of technology adoption and usage, it is possible to argue that prior experience with computers and software in general is more likely (than demographic variables) to confound gender differences. Specifically, a more refined method of dealing with the concept of 
prior experience is to examine the possible confounding role of computer selfefficacy (CSE), defined as the extent to which an individual believes he or she has the ability to use a computer to complete a task (see Compeau \& Higgins 1995). CSE is morelikely to play a rolein influencing decision-making processes since it will reflect the feedback from experiences (i.e., quality of experience) when compared to measures of just the amount of experience. If gender differences are not confounded by these variables, the hypothesized pattern of gender differences should be observed even after statistically controlling the variables.

\section{Measurement}

Validated items from prior research were used to measure attitude toward the behavior of using technology (A), subjective norm (SN), perceived behavioral control (PBC), and behavioral intention to use the system (BI) (Davis et al., 1989; Mathieson, 1991; Taylor \& Todd, 1995). The items used to measure these constructs are consistent with prior TPB research (e.g., Ajzen, 1991). Actual usage behavior (USE), operationalized as the frequency of use (number of user queries for information), was gathered from system logs. In addition to gender itself, potential confounding variables were measured: income, education, and organization position (adapted from Blau \& Duncan, 1967). Computer selfefficacy was measured using 10 items employing a 10-point Guttman scale (Compeau \& Higgins, 1995). The Appendix provides a list of items used in this research.

\section{Results}

We conducted preliminary analyses separately for the data from each of the organizations at each of the three points of measurement to examine the reliability and validity of the different scales used. The pattern of results was consistent across organizations and also in the data set that was pooled across organizations. ${ }^{4}$ Table 1 summarizes the results of the preliminary analysis pooled across organizations. At all three points of measurement, Cronbach al pha estimates for all scales were over .80, suggesting high reliability. At all points of measurement, convergent and discriminant validity were examined using factor analysis with direct oblimin rotation. The factor structure matrix

\footnotetext{
${ }^{4}$ Since the data were collected from different organizations, before testing the hypotheses, we examined whether it was appropriate to pool the data. We tested the basic TPB model in each of the organizations at each of the points of measurement. The basic TPB model was supported in each of the organizations at each of the different point of measurement. The details of the model testing are not reported in this paper in the interest of brevity and also because the validity of TPB in technol ogy adoption contexts has been well established in prior research work (e.g., Harrison et al., 1997; Mathieson, 1991; Taylor \& Todd, 1995). Based on two separate tests (i.e., including a dummy variableand test of beta differences), we found statistical equival ence across all organizations at each point of measurement, suggesting that it was appropriate to pool the data across organizations per the guidelines of Pindyck and Rubenfeld (1981). We al so found statistical equivalence of the descritive statistics across organizations at each point of measurement, thus further supporting the pooling of data across organizations.
} 
TABLE 1

Preliminary Analysis of Data Pooled across Organizations at $t_{1}$ : Reliability and Validity

\begin{tabular}{lllll}
\hline & 1 & 2 & 3 & 4 \\
& BI & A & SN & PBC \\
\hline Cronbach $\alpha$ & .90 & .90 & .90 & .88 \\
BI1 & .9243 & .1404 & .1407 & .0887 \\
BI2 & .9094 & .1702 & .1412 & .0727 \\
A1 & .1421 & .9108 & .1512 & .1045 \\
A2 & .1320 & .9204 & .1006 & .1222 \\
A3 & .1104 & .8562 & .0842 & .1380 \\
A4 & .1001 & .8827 & .0842 & .1380 \\
SN1 & .1402 & .1230 & .9407 & .1904 \\
SN2 & .1072 & .1604 & .9280 & .1802 \\
PBC1 & .1424 & .1021 & .0824 & .8887 \\
PBC2 & .1282 & .0014 & .0271 & .8788 \\
PBC3 & .1156 & .1210 & .0747 & $\mathbf{. 8 8 2 4}$ \\
PBC4 & .1106 & .1316 & .1042 &. $\mathbf{8 5 2 1}$ \\
PBC5 & .1280 & .1604 & .1321 & .9104 \\
\hline
\end{tabular}

Note. The pattern of results replicated at $t_{2}$ and $t_{3}$. Also, the same pattern of results were found when the data were analyzed for each organization taken separately at each of the points of measurement. A1 to A4, attitude items; SN 1 to SN2, subjective norm items; PBC1 to PBC5, perceived behavioral control items; $\mathrm{BI} 1$ to $\mathrm{BI} 2$, behavioral intention items.

suggested convergent validity within scales (loadings greater than .85) and discriminant validity across scales (cross-loadings less than .20).

The descriptive statistics (means and standard deviations) and intercorrelations, categorized by gender, associated with each of the constructs at each of the three points of measurement are given in Table 2 . With the exception of subjective norm at $t_{3}$, the mean values between women and men were statistically different $(p<.05)$ at all points of measurement.

\section{Hypothesis Testing}

Figure 1 presents the research model and hypotheses to betested. Regression analyses were used to examine the TPB relationships and the role of intention and behavior. A dummy variable, GENDER, was introduced to test themoderation of the different relationships by Gender. Figure 3 presents the results of the longitudinal analysis that was conducted. Results indicated that the A-BI, $S N-B I$, and PBC-BI relationships were moderated by GENDER at $t_{1}$, thus supporting $\mathrm{H} 1, \mathrm{H} 2$, and $\mathrm{H} 3$ a. As a predictor of short-term usage (USE12), BI (measured at $\mathrm{t}_{1}$ ) was significant though PBC was not. By further analyzing the data for women and men separately, it appears that while women are influenced by A, SN, and PBC, men are influenced only by A (see Table 3); in fact, the variance explained by these different determinants in women's and men's early intentions was nearly identical. I nter estingly, gender did not moderate the $\mathrm{PBC}-\mathrm{USE}_{12}$ or $\mathrm{BI}-\mathrm{USE}_{12}$ relationships, thus contrary to $\mathrm{H} 3 \mathrm{~b}$ and $\mathrm{H} 4$. 
TABLE 2

Descriptive Statistics and Intercorrelations: Categorized by Gender

\begin{tabular}{|c|c|c|c|c|c|c|c|c|c|c|c|c|c|c|c|c|c|c|c|c|}
\hline & \multicolumn{2}{|c|}{ Women } & \multicolumn{2}{|c|}{ Men } & \multirow[b]{2}{*}{ Gender } & \multirow[b]{2}{*}{$A_{1}$} & \multirow[b]{2}{*}{$\mathrm{SN}_{1}$} & \multirow[b]{2}{*}{$\mathrm{PBC}_{1}$} & \multirow[b]{2}{*}{$\mathrm{BI}_{1}$} & \multirow[b]{2}{*}{$U_{s e}$} & \multirow[b]{2}{*}{$A_{2}$} & \multirow[b]{2}{*}{$\mathrm{SN}_{2}$} & \multirow[b]{2}{*}{$\mathrm{PBC}_{2}$} & \multirow[b]{2}{*}{$\mathrm{BI}_{2}$} & \multirow[b]{2}{*}{$\mathrm{Use}_{23}$} & \multirow[b]{2}{*}{$A_{3}$} & \multirow[b]{2}{*}{$\mathrm{SN}_{3}$} & \multirow[b]{2}{*}{$\mathrm{PBC}_{3}$} & \multirow[b]{2}{*}{$\mathrm{BI}_{3}$} & \multirow[b]{2}{*}{$\mathrm{Use}_{34}$} \\
\hline & $M$ & SD & $M$ & SD & & & & & & & & & & & & & & & & \\
\hline$A_{1}$ & 4.12 & 1.03 & 5.10 & 0.90 & $.34 * * *$ & & $.21^{*}$ & $.24 * *$ & $.28 * * *$ & $.20 * *$ & $.28 * * *$ & $.20 * *$ & .15 & $.20 *$ & $.25^{* *}$ & $.29 * * *$ & $.20^{*}$ & $.20 *$ & $.21^{*}$ & $.25^{* *}$ \\
\hline $\mathrm{SN}_{1}$ & 3.92 & 0.82 & 5.12 & 0.82 & $.31 * * *$ & $.20 * *$ & & $.23^{* *}$ & $.55^{* * *}$ & $.32 * * *$ & $.19 *$ & $.19 *$ & .07 & $.20 *$ & $.32 * * *$ & .10 & $.30 * * *$ & $.22 * *$ & $.25 * * *$ & $.25 * * *$ \\
\hline $\mathrm{PBC}_{1}$ & 4.11 & 0.69 & 5.40 & 0.74 & $.25 * *$ & $.21 * *$ & $.27 * * *$ & & $.41 * * *$ & $.20 *$ & .06 & $.16^{*}$ & $.37 * * *$ & $.30 * * *$ & $.17 *$ & .13 & .18 & $.27^{* *}$ & $.20 *$ & $.26 * *$ \\
\hline $\mathrm{BI}_{1}$ & 3.73 & 0.91 & 5.23 & 1.02 & $.25^{* *}$ & $.46 * * *$ & $.17 *$ & $.20 *$ & & $.50 * * *$ & $.33 * * *$ & $.16^{*}$ & $.30 * * *$ & $.43^{* * *}$ & $.41 * * *$ & $.20 *$ & $.24 * *$ & $.19 *$ & $.45^{* * *}$ & $.40 * * *$ \\
\hline $\mathrm{Use}_{12}$ & 3.23 & 1.40 & 7.93 & 1.88 & $.30 * * *$ & $.35 * * *$ & $.20 * *$ & .15 & $.51 * * *$ & & $.35 * * *$ & $.20 * *$ & $.25 * *$ & $.39 * * *$ & $.50 * * *$ & $.28 * * *$ & $.20 *$ & $.30 * *$ & $.35 * * *$ & $.47 * * *$ \\
\hline$A_{2}$ & 4.12 & 1.04 & 5.18 & 0.71 & $.35 * * *$ & $.32 * * *$ & .15 & .13 & $.30 * * *$ & $.30 * * *$ & & .10 & $.17^{*}$ & $.35 * * *$ & $.27 * * *$ & $.25 * *$ & $.18^{*}$ & $.20^{*}$ & $.24 * *$ & $.25 * *$ \\
\hline $\mathrm{SN}_{2}$ & 3.80 & 0.89 & 4.87 & 0.79 & $.35^{* * *}$ & $.21^{*}$ & $.18^{*}$ & $.15^{*}$ & .10 & .12 & .14 & & $.23^{* *}$ & $.17 *$ & $.19 *$ & .16 & $.24 * *$ & $.19 *$ & $.22 *$ & .15 \\
\hline $\mathrm{PBC}_{2}$ & 3.94 & 0.92 & 5.55 & 0.82 & $.37 * * *$ & .07 & .02 & $.32 * * *$ & $.30 * * *$ & .16 & $.20 *$ & $.19 *$ & & $.35^{* * *}$ & $.27 * *$ & $.24 * *$ & $.21^{* *}$ & $.28 * * *$ & $.18^{*}$ & $.20 *$ \\
\hline $\mathrm{BI}_{2}$ & 3.58 & 0.80 & 5.02 & 1.03 & $.33 * * *$ & $.25^{* *}$ & $.20 *$ & $.22 *$ & $.48 * * *$ & $.40 * * *$ & $.40 * * *$ & $.17 *$ & $.20^{*}$ & & $.51^{* * *}$ & $.24 * *$ & .09 & $.29 * * *$ & $.49 * * *$ & $.42 * * *$ \\
\hline USE $_{23}$ & 6.86 & 1.31 & 10.12 & 2.52 & $.37 * * *$ & $.31 * * *$ & $.20 *$ & .10 & $.45^{* * *}$ & $.55^{* * *}$ & $.32 * * *$ & $.22 *$ & $.26^{* *}$ & $.50 * * *$ & & $.20 * *$ & $.24 * *$ & $.35 * * *$ & $.38 * * *$ & $.54 * * *$ \\
\hline$A_{3}$ & 4.02 & 0.90 & 5.22 & 0.84 & $.37 * * *$ & $.30 * *$ & .05 & .12 & $.20 *$ & $.31 * * *$ & $.30 * * *$ & .15 & $.20^{* *}$ & $.30 * *$ & $.37 * * *$ & & $.21^{* *}$ & $.24 * *$ & $.22 *$ & $.24 * *$ \\
\hline $\mathrm{SN}_{3}$ & 3.98 & 1.00 & 4.38 & 0.88 & $.21 * *$ & .15 & $.13^{*}$ & .15 & $.20 *$ & .12 & .10 & $.20 *$ & .10 & .09 & .10 & $.19 * *$ & & $.27^{* * *}$ & $.19 *$ & .07 \\
\hline $\mathrm{PBC}_{3}$ & 3.88 & 1.04 & 5.70 & 0.82 & $.35 * * *$ & $.24 * *$ & .10 & $.30 * * *$ & $.18^{*}$ & $.20 *$ & $.18^{*}$ & $.20 *$ & $.29 * * *$ & $.30 * * *$ & $.24 * *$ & $.25 * *$ & .10 & & $.50 * * *$ & $.29 * * *$ \\
\hline $\mathrm{BI}_{3}$ & 3.68 & 1.10 & 5.01 & 0.83 & $.35 * * *$ & $.20^{*}$ & .10 & $.20 *$ & $.48 * * *$ & $.38 * * *$ & $.25^{* *}$ & $.25 *$ & $.15^{*}$ & $.54 * * *$ & $.42 * * *$ & $.40 * * *$ & $.20 *$ & .16 & & $.49 * * *$ \\
\hline $\mathrm{Use}_{34}$ & 7.11 & 1.41 & 9.91 & 2.82 & $.32 * * *$ & $.32 * *$ & .16 & .15 & $.44 * * *$ & $.48 * * *$ & $.31 * * *$ & .15 & $.19 *$ & $.45 * * *$ & $.55 * * *$ & $.35 * * *$ & .10 & $.28 * * *$ & $.52 * * *$ & \\
\hline
\end{tabular}

Notes. $A_{1}, \mathrm{SN}_{1}, \mathrm{PBC}_{1}$, and $\mathrm{BI}_{1}$, measurements at $\mathrm{t}_{1} . \mathrm{A}_{2}, \mathrm{SN}_{2}, \mathrm{PBC}_{2}$, and $\mathrm{BI}_{2}$, measurements at $\mathrm{t}_{2} . \mathrm{A}_{3}, \mathrm{SN}_{3}, \mathrm{PBC}_{3}$, and $\mathrm{BI}_{3}$, measurements at $t_{3}$. Use $\mathrm{H}_{12}$, usage measured between $t_{1}$ and $t_{2}$. Use $e_{23}$, usage measured between $t_{2}$ and $t_{3}$. Use $e_{34}$, usage measured between $t_{3}$ and $t_{4}$.

The correlations among $\mathrm{A}, \mathrm{SN}$, and PBC below the diagonal are for men, and the correlations above the diagonal are for women.

$* \mathrm{p}<.05 ; * * \mathrm{p}<.01 ; * * * \mathrm{p}<.001$. 


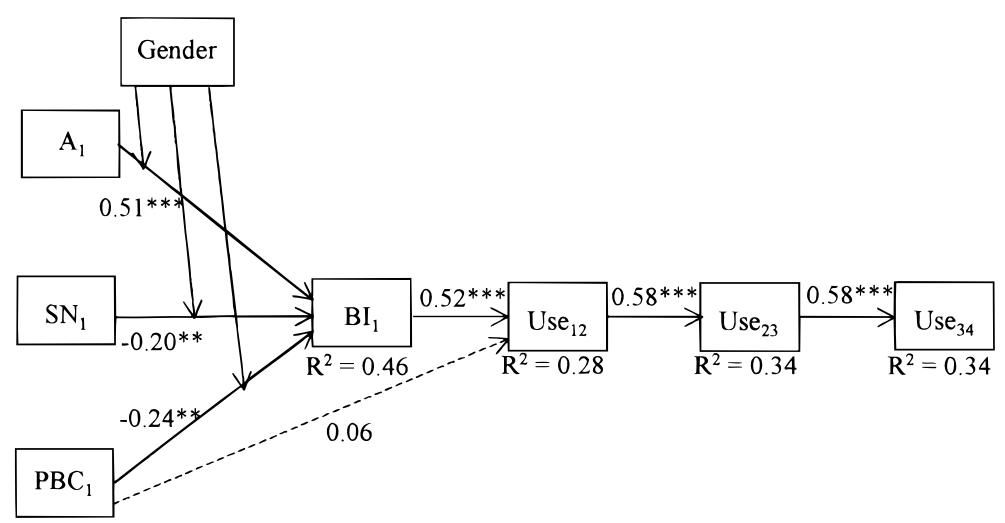

FIG. 3. Results.

The final step was to understand subsequent intention $\left(\mathrm{BI}_{2}\right.$ and $\left.\mathrm{BI}_{3}\right)$ and sustained usage behavior ( $\mathrm{USE}_{23}$ and $\mathrm{USE}_{34}$ ). Only use measured in the previous time period was a significant predictor of sustained usage behavior -the other TPB constructs, including BI, were nonsignificant as predictors of sustained usage, with or without including gender as a moderating variable, thus rendering $\mathrm{H} 5 \mathrm{a}, \mathrm{H} 5 \mathrm{c}$, and $\mathrm{H} 5 \mathrm{~d}$ moot in the present context. Interestingly, gender did not moderate the $\mathrm{USE}_{12}-\mathrm{USE}_{23}$ or the $\mathrm{USE}_{23}-\mathrm{USE}_{34}$ relationships, contrary to $\mathrm{H} 5 \mathrm{~b}$.

\section{Role of Confounds}

In order to rule out potential confounding of gender differences by income, organizational level, education, and computer self-efficacy, we conducted a three-stage hierarchical regression to examine: (a) the variance explained by A, SN, and PBC, (b) possible moderating effects of the confounding variables, and (c) incremental variance explained by gender as a moderating variable. Each of the confounding variables was coded as a continuous variable consistent

TABLE 3

Gender Differences in the Salience (Beta Coefficients) of A, SN, and PBC as Determinants of Early Intentions $\left(t_{1}\right)$

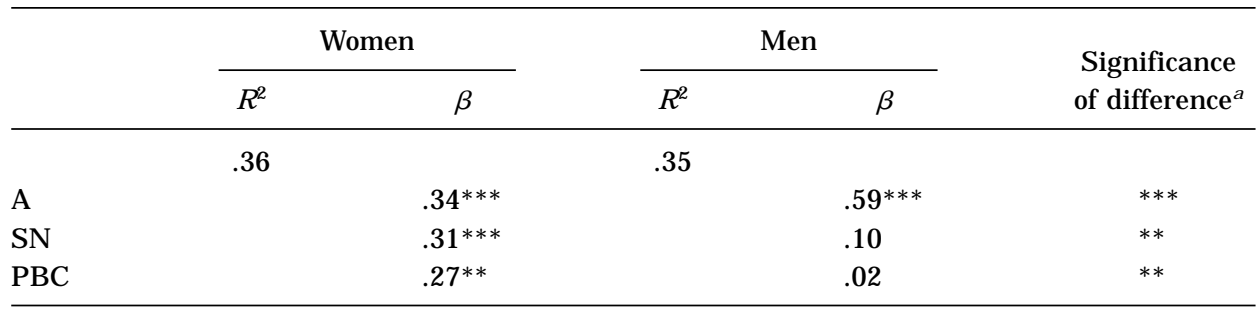

Note. The PBC-USE 12 relationship was nonsignificant for women and men.

a Significance of differencerepresents thesignificance of theinteraction term (e.g., A $\times$ GENDER) (Fig. 3) and was also confirmed by test of beta differences across independent samples.

$* \mathrm{p}<.05 ; * * \mathrm{p}<.01 ; * * * \mathrm{p}<.001$. 
TABLE 4

Hierarchical Regression Analysis: Gender, Confounds, and Their Relative Influence on Early Intentions $\left(t_{1}\right)$

\begin{tabular}{|c|c|c|c|c|}
\hline Step & Variables entered & $\mathrm{R}^{2}$ & $\Delta \mathrm{R}^{2}$ & $\beta$ \\
\hline \multirow[t]{3}{*}{1} & $A$ & .34 & .34 & $.42 * * *$ \\
\hline & SN & & & $.19 *$ \\
\hline & PBC & & & $.15^{*}$ \\
\hline \multirow[t]{16}{*}{2} & INCOME & .35 & .01 & .07 \\
\hline & ORG LEVEL & & & .02 \\
\hline & EDUCATION & & & .02 \\
\hline & CSE & & & .05 \\
\hline & INCOME $\times A$ & & & -.11 \\
\hline & INCOME $\times S N$ & & & -.13 \\
\hline & INCOME $\times$ PBC & & & .06 \\
\hline & ORG LEVEL $\times A$ & & & .13 \\
\hline & ORG LEVEL $\times$ SN & & & .02 \\
\hline & ORG LEVEL $\times$ PBC & & & .10 \\
\hline & EDUCATION $\times A$ & & & .12 \\
\hline & EDUCATION × SN & & & .05 \\
\hline & EDUCATION $\times$ PBC & & & .02 \\
\hline & $\mathrm{CSE} \times \mathrm{A}$ & & & .03 \\
\hline & $\mathrm{CSE} \times \mathrm{SN}$ & & & .10 \\
\hline & $\mathrm{CSE} \times \mathrm{PBC}$ & & & .12 \\
\hline \multirow[t]{4}{*}{3} & GENDER & .46 & .11 & .04 \\
\hline & GENDER $\times A$ & & & $.51^{* * *}$ \\
\hline & GENDER $\times$ SN & & & $-.20^{* *}$ \\
\hline & GENDER $\times$ PBC & & & $-.24^{* *}$ \\
\hline
\end{tabular}

$* \mathrm{p}<.05 ; * * \mathrm{p}<.01 ; * * * \mathrm{p}<.001$.

with the measurement scale identified in the Appendix. As is evident from Table 4, none of the variables confounded the gender differences observed. In fact, the main effects and interaction terms including income, organizational level, education, and computer self-efficacy were all found to be nonsignificant as predictors of intention. ${ }^{5}$ Similarly, we found that none of the confounding variables moderated the $\mathrm{BI}-\mathrm{USE}_{12}, \mathrm{PBC}-\mathrm{USE}_{12}, \mathrm{USE}_{12}-\mathrm{USE}_{23}$, or USE $\mathrm{US}_{23^{-}}$ USE $_{34}$ relationships. ${ }^{6}$

\section{DISCUSSION}

This research reveals that there are clear gender differences in the salience of various factors determining an individual's technology adoption decisions in the workplace. Despite some nonsignificant effects, the role of gender in

${ }^{5}$ Given the nonsignificance of the three-way interaction terms, retaining the null hypothesis raises issues about potential type II error (see Cohen, 1988). Power analyses revealed that we would have been able to detect medium effect sizes with a power of almost .80 and small effect sizes with a power of over .70 .

${ }^{6}$ These results are not reported given that even gender did not moderate these relationships. 
technology adoption and usage behavior is crucial. Clearly, gender shapes the initial decision process that drives new technol ogy adoption and usage behavior in the short-term, which in turn influences sustained usage, thus establishing that early intentions formed by women and men will have a lasting influence on their usage of the said new technology-it is critical to recognize that the underlying drivers of these stable early intentions are different for women and men. Gender differences were observed even when key potential confounding variables (i.e., income, organization level, education, and computer self-efficacy) were taken into account.

In this research, the longitudinal investigation of the determinants of technology adoption and usage behavior confirmed that attitude toward using technology was more salient to men. Subjective norm did not significantly influence men's decisions. However, women were strongly influenced by subjective norm and perceived behavioral control. A longitudinal analysis of the data revealed that intention predicted short-term use, which in turn predicted sustained use. However, these subsequent relationships (i.e., intention to shortterm use, short-term use to sustained use) were not moderated by gender. From the perspective of TPB, this work suggests the role of gender as a key moderating variable in the context of technol ogy adoption and usage behavior.

This research has several key theoretical and practical contributions and implications. We expected attitude to be more salient for men, and subjective norm and perceived behavioral control to be more salient for women. Interestingly, and somewhat contrary to TPB itself, subjective norm and perceived behavioral control were nonsignificant factors among men. From a theoretical standpoint, this represents an important contribution since the basic model underlying technology adoption decisions of men in the workplace regarding technology adoption and usage appears to be significantly different from what is specified by TPB. This suggests that while men are more focused in their decision-making process regarding technology adoption and usage, women are more balanced. Such a line of reasoning is further supported by the nearly identical variancein intention explained by thesignificant determinants among women (A, SN, and PBC) and men (A). Further, the striking uniformity of the results, even after controlling for the direct and interaction effects of confounding variables, suggests that gender plays an important role in shaping individual technol ogy adoption and sustained usage in the workplace. Thus, including gender as a potential moderator of the TPB relationships helps us gain a more complete understanding of the underlying cognitive phenomena related to technology adoption. ${ }^{7}$

With thegrowing presence of women in the workforceat all levels, the present work brings to the forefront the need to be cognizant of gender differences in the decision-making processes. This is not meant to open a Pandora's box of issues related to gender discrimination, but rather to emphasize the need to

${ }^{7}$ Using a different data set and a different theoretical perspective-Technology Acceptance Model - Venkatesh and Morris (2000) presents a cross-sectional understanding of gender differences in technology and usage behavior. 
be sensitive to possible diversity in decision-making processes between women and men. For example, sensitivity to gender differences can result in implications for both training and marketing. To maximizeoverall acceptance, training programs might be tailored to emphasize factors that are salient to each group. For example, trainers should be cognizant of the need to emphasize productivity-enhancement factors (e.g., usefulness) which are more important to men. They should al so take care to ensure this emphasis does not comeat the expense of other factors that may be more salient to women (e.g., claims by peers or other referents and availability of adequate support). Similarly, marketing professionals may also capitalize on these findings by designing advertising campaigns which appeal to both women and men, thereby giving each group something to like about a new technology product.

The usage data collected over thefive-month period fol lowing implementation of the new system revealed that early intention-i.e., formed on the basis of TPB constructs, albeit different for women and men-was the key driver of short-term use which in turn dictated sustained use. This pattern highlights theimportance of thelasting influence of gender differences and the consequent intentions on the successful implementation of new technologies. It thus behooves organizational psychologists and practitioners to pay close attention to the maxim "you never get a second chance to make a first impression." In fact, recent theoretical discussions support our findings (see Bargh \& Chartrand, 1999). In summarizing a broad range of research on automatic processes and habitual behaviors, they suggest that the frequent and consistent use of the samemental processes in particular situations results in automatization which in turn results in an individual unintentionally making the same choice when faced with the situation again. Although the issues of habit and its role in dictating future behavior have been discussed in the literature for over a century (see J ames, 1890), the current work presents one of the very first pieces of empirical evidence in the context of technology use in the workplace. In highlighting the importance of prior behavior in predicting future behavior, the current work also draws our attention to the fact that the window to effect changes in technology adoption and usage contexts may, in fact, be quite small and available only in the early stages of new technology implementations.

\section{LIMITATIONS AND SUGGESTIONS FOR FUTURE RESEARCH}

As with all behavioral research, therearea number of limitations that should be noted in this research. First, this study relied on a "reduced" model based on TPB. In much of the work on TPB, researchers al so focus on the underlying belief structures for the attitudinal and perceptual components of the model (i.e., A, SN, and PBC). This paper did not attempt to el icit the specific underlying belief structures for the basic TPB constructs within this sample; rather, we relied on extensive prior research in the technology adoption domain (e.g., Taylor \& Todd, 1995) as the basis for the underlying beliefs. Adding these more elementary cognitions to the survey instrument would have likely resulted in an instrument five times as long as that used in the present study, which may 
have compromised other aspects of the study (e.g., response rate and power). Given the encouraging findings regarding gender differences in technology adoption and usage decisions, future work should examine this phenomenon by including the underlying belief structure to create the potential to develop organizational interventions to enhance technology adoption and usage.

Another TPB-related area for future research to focus on in the context of technol ogy adoption in general and the associated gender differences in particular is the use of behavioral expectation (rather than behavioral intention) as a key predictor of behavior. The use of behavioral expectation as a predictor has been shown to be important in cases where the conditions of conscious volitionality are not met (e.g., Warshaw \& Davis, 1985a). Also, as behaviors become more habituated, behavioral expectation has shown to be a better predictor of behavior (e.g., Warshaw \& Davis, 1986b). Interestingly, in some contexts, research has shown that the intention items in fact measure expectation (e.g., Davis \& Warshaw, 1985).

While peer pressure and superiors' influence are key determinants of subjective norm in technology adoption contexts, one crucial direction for future research is the underlying mechanism for the greater importance placed by women on such normative influences. As discussed earlier, Minton and Schneider (1980) and Roberts (1991) suggest two potentially competing causal mechanisms. Although both lines of argument suggested similar outcomes, the information processing models proposed are different. It is important to understand these models and circumstances under which each model is operational in order to facilitate design of appropriate organizational interventions for increased buy-in for technologies being introduced.

Another aspect of these results that is worthy of mention is that our research on gender differences of technology adoption has focused on the workplace in the Western culture. This issue should be addressed in other settings where technol ogy is becoming pervasive (e.g., homes). Similar to many organizational psychol ogy theories devel oped and tested in North America that may not generalize to other cultures, the present work bears vali idity only to the broad context in which the studies have been conducted. Thus, the research should be replicated in devel oping countries (e.g., India), particularly since technol ogy use in these countries has increased dramatically in the past few years.

In organizational psychology, as in most fields using survey-based measures, results are specific to the measures used. In this research, we employed wellestablished measures for all constructs. Yet, we believe, there is a need for further refinement of the measures to more firmly support our conclusions. F uture research is necessary to deepen our understanding of gender differences in technology adoption by focusing on further refinement of the measurement of the various demographic variables employed. For example, as mentioned at the outset, the measurement of gender as a dichotomous variable is consistent with what is termed biological sex rather than gender. Therefore, future research should investigate individual technology adoption by studying gender as a psychological construct based on femininity and masculinity (Bem, 1981) to further our understanding of how individuals make decisions to adopt and 
use technology in the workplace. One potential extension of income-based gender differences could be to examine the role of household income since it may more accurately reflect and reveal patterns of individual socialization and ways of thinking, in relationship to socio-economic status. The measure of organization level was adapted from prior research and was tailored to suit the organizations studied, but other schemes of operationalizing organization level are also worthy of study. Similarly, further work on understanding the role of education level should use other measures of intelligence (e.g., IQ tests) or domain knowledge (e.g., computer aptitude tests). While we measured age in the present work, the participating organizations were specifically sensitive and therefore opposed to publications discussing findings by incorporating age as a potential confound. However, in related work (Morris \& Venkatesh, 2000), in one organization, we examine age differences in technol ogy adoption; unfortunately, in that case, the participating organization did not allow the gathering of gender data. Thus, cumulatively, this calls for research examining gender and age differences in a single study.

\section{CONCLUSIONS}

Does gender matter when examining technology adoption and usage in the workplace? This research suggests that, in fact, it does. The findings reveal that men and women adopt very different decision processes in evaluating new technologies. While TPB provides a relatively good fit in explaining intention and usage behavior for both women and men, each group appears to value or weight each of the underlying factors differently. I mportantly, gender differences reported in this research were robust to key confounds identified in prior organizational behavior literature. While men may still represent a majority of the workforce, particularly in technology-oriented areas, the number of women in these areas and all levels of the organizational hierarchy continues to rise. As a result, managers implementing new technology must understand the factors that are likely to lead to user acceptance and sustained usage by users. To that end, the results suggest that when making technology adoption decisions, managers must consider not only traditional productivity-oriented factors, but also social factors and facilitating conditions as well. In the end, the axiom "know thy user" would appear to be especially important since various user constituencies (e.g., women and men) process information and make decisions about technology in very different ways.

\section{APPENDIX}

\section{Questionnaire Items}

Gender: $\quad \square$ Female

$\square$ Male

Education Level: $\quad \square$ Some high school or less $\square$ Some college 
$\begin{array}{ll}\square \text { Graduated high school } & \square \text { Graduated college } \\ \square \text { Vocational/technical school } & \square \text { Post-graduate study }\end{array}$

Annual Individual Income:

Less than $\$ 20,000$

口 $\$ 60,000-\$ 69,999$

(Before Taxes)

$\$ 20,000-\$ 29,999$

$\square \$ 70,000-\$ 79,999$

$\square \$ 30,000-\$ 39,999$

$\$ 80,000-\$ 89,999$

$\square \$ 40,000-\$ 49,999$

$\$ 90,000$ - $\$ 99,999$

口 $\$ 50,000-\$ 59,999$

- \$100,000 or more

Position:
$\square$ Executive/Top Management
Middle Management
$\square$ Supervisory

$\square$ Administrative/Clerical

$\square$ Technical

$\square$ Other:

(please specify)

\title{
Intention to Use (7-point Likert scale)
}

Assuming I had access to the system, I intend to use it.

Given that I had access to the system, I predict that I would use it.

\begin{abstract}
Using the system is a (bad/good) idea.
Using the system is a (foolish/wise) idea.

I (dislike/like) the idea of using the system.

Using the system is (unpleasant/pleasant).
\end{abstract}

Attitude Toward Using (7-point semantic differential scale)

\section{Subjective Norm (7-point Likert scale)}

People who influence my behavior think that I should use the system.

People who are important to me think that I should use the system.

\section{Perceived Behavioral Control (7-point Likert scale)}

I have control over using the system.

I have the resources necessary to use the system.

I have the knowledge necessary to use the system.

Given the resources, opportunities and knowledge it takes to use the system, it would be easy for me to use the system.

The system is not compatible with other systems I use.

\section{Computer Self-E fficacy (10-point Guttman scale)}

(Note: Additional instructions were provided per Compeau and Higgins 1995).

I could complete the job using a software package. . .

... if there were no one around to tell me what to do as I go.

... if I had never used a package like it before.

... if I had only the software manuals for reference.

... . if I had seen someone else using it before trying it myself.

... if I could call someone for help if I got stuck.

... if someone else had helped me get started.

... if I had a lot of time to complete the job for which the software was provided.

... if I had just the built-in help facility for assistance.

... if someone showed me how to do it first.

... if I has used similar packages before this one to do the same job. 


\section{REFERENCES}

Ajzen, I. (1985). From intentions to actions: A theory of planned behavior. In J . Kuhl \& J . Beckmann (Eds.), Action control: From cognition to behavior (pp. 11-39). New York: Springer-Verlag.

Ajzen, I. (1991). The theory of planned behavior. Organizational Behavior and Human Decision Processes, 50, 179-211.

Ajzen, I., \& Driver, B. (1992). Application of the theory of planned behavior to leisure choice. J ournal of Leisure Research, 24, 207-224.

Ajzen, I., \& Madden, T. J . (1986). Prediction of goal-directed behavior: Attitudes, intentions, and perceived behavioral control. J ournal of Experimental Social Psychology, 22, 453-474.

Bagozzi, R. P. (1981). Attitudes, intentions, and behavior: A test of some key hypotheses. J ournal of Personality and Social Psychology, 41, 607-627.

Bagozzi, R. P., Baumgartner, H., \& Yi, Y. (1992). State versus action orientation and the theory of reasoned action: An application to coupon usage. J ournal of Consumer Research, 18, 505-518.

Bagozzi, R. P., \& Kimmel, S. K. (1995). A comparison of leading theories for the prediction of goaldirected behaviors. British J ournal of Social Psychology, 34, 437-461.

Baird, J . E., J r. (1976). Sex differences in task and social-emotional behavior. Basic and Applied Social Psychology, 3, 109-139.

Bargh, J . A., \& Chartrand, T. L. (1999). The unbearable automaticity of being. American Psychologist, 54, 462-479.

Barnett, J . H., \& Karson, M. J . (1989). Managers, values, and executive decisions: An exploration of the role of gender, career stage, organizational level, function, and the importance of ethics, relationships and results in managerial decision-making. J ournal of Business Ethics, 8, 747-781.

Barnett, R. C., \& Marshall, N. L. (1991). The relationship between women's work and family roles and their subjective well-being and psychological distress. In M. Frankenhaeuser, V. Lundberg, \& M. A. Chesney (Eds.), Women, work and health: Stress and opportunities (pp. 111-136). New York: Plenum.

Baucom, D. H. (1983). Sex role identity and the decision to regain control among women: A learned helplessness investigation. J ournal of Personality and Social Psychology, 44, 334- 353.

Baucom, D. H., \& Danker-Brown, P. (1984). Sex role identity and sex-stereotyped tasks in the development of learned hel plessness in women. J ournal of Personality and Social Psychology, 46, 422- 430.

Becker, B. J . (1986). Influence again: An examination of reviews and studies of gender differences in social influence. In J . S. Hyde \& M. C. Linn (Eds.), Thepsychol ogy of gender: Advances through meta-analysis (pp. 178-209). Baltimore, MD: J ohns Hopkins Univ. Press.

Bem, D. J ., \& Allen, A. (1974). On predicting some of the people some of the time: The search for cross-situational consistencies in behavior. Psychological Review, 81, 506-520.

Bem, S. L. (1981). The BSRI and gender schema theory: A reply to Spence and Helmreich. Psychological Review, 88, 369-371.

Bentler, P. M., \& Speckart, G. (1979). Attitudes cause behaviors: A structured equation analysis. J ournal of Personality and Social Psychology, 40, 226-238.

Berger, I . (1993). A framework for understanding the relationship between environmental attitudes and consumer behavior. In R. Varadarjan \& B. J aworski (Eds.), Marketing theory and application (vol. 4, pp. 157-163). Chicago: American Marketing Association.

Bergeron, F., Rivard, S., \& De Serre, L. (1990). Investigating the support role of the information center. MIS Quarterly, 14, 247-259.

Blau, P. M., \& Duncan, O. D. (1967). The American occupational structure. New York: Free Press.

Bozionelos, N. (1996). Psychology of computer use: XXXIX. Prevalence of computer anxiety in British managers and professionals. Psychological Reports, 78, 995- 1002. 
Brenner, O. C., Blazini, A. P., \& Greenhaus, J . H. (1988). An examination of race and sex differences in managerial work values. J ournal of Vocational Behavior, 32, 336-344.

Carlson, R. (1971). Sex differences in ego functioning: Exploratory studies of agency and communion. J ournal of Consulting and Clinical Psychology, 37, 267-277.

Chen, M. (1985). Gender differences in adolescents' uses of and attitudes toward computers. In M. McLaughlan (Ed.), Communication yearbook, (vol. 10, pp. 200-216), Beverly Hills: Sage.

Chodorow, N. (1974). Family structure and feminine personality. In M. Z. Rosaldo and L. Lamphere (Eds.), Women, culture, and society. Palo Alto: Stanford Univ. Press.

Cohen, J . (1988). Statistical power analysis for the behavioral sciences, 2nd ed. Hillsdale, NJ : Erlbaum.

Compeau, D. R., \& Higgins, C. A. (1995). Computer self-efficacy: Development of a measure and initial test. MIS Quarterly 19, 189-211.

Conner, M., \& Armitage, C. J . (1998). Extending the theory of planned behavior: A review and avenues for further research. J ournal of Applied Social Psychology, 28, 1429- 1464.

Cragg, P. B., \& King, M. (1993). Small-firm computing: Motivators and Inhibitors. MIS Quarterly, 17, 47-60.

Crawford, M., Chaffin, R., \& Fitton, L. (1995). Cognition in social context. Special Issue: PsychoIogical and Psychobiol ogical Perspectives on Sex Differences in Cognition: I. Theory and Research. Learning and Individual Differences, 7, 341-362.

Crow, S. M., Fok, L. Y., Hartman, S. J ., \& Payne, D. M. (1991). Gender and values: What is the impact on decision making? Sex Roles, 25, 255-268.

Davis, F. D. (1989). Perceived usefulness, perceived ease of use, and user acceptance of information technology. MIS Quarterly, 13, 319-339.

Davis, F. D., Bagozzi, R. P., \& Warshaw, P. R. (1989). User acceptance of computer technology: A comparison of two theoretical models. Management Science, 35, 982-1002.

Davis, F. D., \& Warshaw, P. R. (1985). What do intention scales measure? J ournal of General Psychology, 119, 391-407.

Dawson, L. M. (1995). Women and men, morality and ethics. Business Horizons, 38, 61-69.

Deaux, K. (1985). Sex and gender. In M. R. Rosenzweig \& L. W. Porter (Eds.), Annual review of psychology (vol. 36, pp. 49-81). Palo Alto: Annual Reviews.

Eagly, A. H. (1978). Sex differences in influenceability. Psychological Bulletin, 85, 86- 116.

Eagly, A. H., \& Carli, L. L. (1981). Sex of researchers and sex-typed communications as determinants of sex differences in influenceability: A meta-analysis of social influence studies. Psychological Bulletin, 90, 1-20.

Eccles, J . (1987). Gender roles and women's achievement-related decisions. Psychology of Women Quarterly, 11, 135-171.

Erikson, E. W. (1968). I dentity: Youth and crisis. New York: Norton.

Fazio, R. H., \& Zanna, M. (1978a). Attitudinal qualities relating to the strength of the attitudeperception and attitude-behavior relationship. J ournal of Experimental Social Psychology, 14, 398-408.

Fazio, R. H., \& Zanna, M. (1978b). On the predictive validity of attitudes: The roles of direct experience and confidence. J ournal of Personality, 46, 228-243.

Fazio, R. H., \& Zanna, M. (1981). Direct experience and attitude-behavior consistency. In L. Berkowitz (Ed.), Advances in experimental social psychology (vol. 14, pp. 161-202). San Diego: Academic Press.

Felter, M. (1985). Sex differences on the California statewide assessment of computer literacy. Sex Roles, 13, 181- 192. 
Franke, G. R., Crown, D. F., \& Spake, D. F. (1997). Gender differences in ethical perceptions of business practices: A social role theory perspective. J ournal of Applied Psychology, 82, 920-934.

Galbraith, S., \& Stephenson, H. B. (1993). Decision rules used by male and female business students in ethical value judgements. J ournal of Business Ethics, 12, 227-233.

Garai, J. E., \& Scheinfeld, A. (1968). Sex differences in mental and behavioral traits. Genetic Psychology Monographs, 77, 169-299.

Gianakos, I., \& Subich, L. M. (1988). Student sex and sex role in relation to college major choice. Career Development Quarterly, 36, 259-268.

Gill, S., Stockard, J ., J ohnson, M., \& William, S. (1987). Measuring gender differences: The expressive dimension and critique of androgyny scales. Sex Roles, 17, 375-400.

Gilligan, C. (1982). In a different voice. Cambridge, MA: Harvard Univ. Press.

Gould, S., \& Werbel, J . (1983). Work involvement: A comparison of dual wage earner and single wage earner families. J ournal of Applied Psychology, 68, 313-319.

Harrison, D. A., Mykytyn, P. P., \& Riemenschneider, C. K. (1997). Executive decisions about adoption of information technology in small business: Theory and empirical tests. Information Systems Research, 8, 171- 195.

Heckhausen, H., \& Beckmann, J . (1990). Intentional action and action slips. Psychol ogical Review, 97, 36- 48.

Hennig, M., \& J ardim, A. (1977). The managerial woman. Garden City, NY: Anchor Press.

Hodgson, R. C., \& Watson, E. D. (1987). Gender-integrated management teams. Business Quarterly, 52, 68- 72 .

Hoffman, L. W. (1972). Early childhood experiences and women's achievement motives. J ournal of Social Issues, 28, 129-155.

J ames, W. (1890). Principles of psychology. New York: Holt.

J ohansen, R., \& Swigart, R. (1996). Upsizing theindividual in thedownsized organization: Managing in thewake of reengineering, gl obalization, and overwhel ming technol ogical change Reading, MA: Addison-Wesley.

Kagan, J . (1964). Acquisition and significance of sex-typing and sex roleidentity. In M. L. H offman \& L. W. Hoffman (Eds.), Review of child devel opment research (vol. 1, pp. 137-167). New York: Sage.

Kanter, R. M. (1977). Men and women of the corporation. New York: Basic Books.

Kanter, R. M. (1987). Men and women of the corporation revisited. Management Review, 76, 14- 16.

Kelman, H. C. (1958). Compliance, identification, and internalization: Three processes of opinion change. J ournal of Conflict Resolution, 2, 51-60.

Kohlberg, L., \& Kramer, R. (1969). Continuities and discontinuities in childhood and adult moral development. Human Development, 12, 3-120.

Kohlberg, L. A. (1966). A cognitive-developmental analysis of children's sex-role concepts and attitudes. In E. E. Maccoby (Ed.), The development of sex differences (pp. 82-173). Stanford: Stanford Univ. Press.

Landau, S. B., \& Leventhal, G. A. (1976). A simulation study of administrators' behavior toward employees who receive job offers. J ournal of Applied Social Psychology, 6, 291-306.

Landauer, T. K. (1995). The trouble with computers: Usefulness, usability, and productivity. Cambridge, MA: MIT Press.

Lefkowitz, J . (1994). Sex-related differences in job attitudes and dispositional variables: Now you see them, .... Academy of Management J ournal, 37, 323-349.

Lu, M. (1999). Do people move when they say they will? Inconsistencies in individual migration behavior. Population and Environment: A J ournal of Interdisciplinary Studies, 20, 467-488.

Lundeberg, M. A., F ox, P. W., \& Puncochar, J . (1994). Highly confident but wrong: Gender differences and similarities in confidence judgments. J ournal of Educational Psychology, 86, 114-121. 
Maccoby, E. E., \& J acklin, C. N. (1974). The psychology of sex differences. Stanford: Stanford Univ. Press.

Mathieson, K. (1991). Predicting user intentions: Comparing the technology acceptance model with the theory of planned behavior. Information Systems Research, 2, 173-191.

Miller, J . B. (1976). Toward a new psychology of women. Boston: Beacon Press.

Minton, C., Kagan, J ., \& Levine, J . A. (1971). Maternal control and obedience in the two-year-old. Child Development, 42, 1873-1894.

Minton, H. L., \& Schneider, F. W. (1980). Differential psychology. Prospect Heights, IL: Waveland Press.

Mirowsky, J ., \& Ross, C. E. (1990). Control or defense? Depression and the sense of control over good and bad outcomes. J ournal of Health and Social Behavior, 31, 71-86.

Moore, G. A. (1991). Crossing the chasm: Marketing and selling high-tech products to mainstream customers, New York: Harper-Collins.

Morris, M. G., \& Venkatesh, V. (In press). Age differences in technology adoption decisions: I mplications for a changing workforce. Personnel Psychology.

Morrow, P. C., Presll, E. R., \& McEIroy, J . C. (1986). Attitudinal and behavioral correlates of computer anxiety. Psychological Reports, 59, 1199-1204.

Nisbett, R. E., \& Ross, L. (1980). Human inference: Strategies and shortcomings of social judgement. Englewood Cliffs, NJ : Prentice-Hall.

Norman, D. A. (1993). Things that make us smart: Defending human attributes in the age of the machine. Reading, MA: Addison-Wesley.

Norman, P., \& Smith, L. (1995). The theory of planned behaviour and exercise: An investigation into the role of prior behaviour, behavioural intentions and attitude variabilty. European J ournal of Social Psychology, 25, 403-415.

O'Neil, J . M. (1982). Gender-role conflict and strain in men's lives: I mplications for psychiatrists, psychologists, and other human-service providers. In K. Solomon \& N.B. Levy (Eds.), Men in transition: Theory and therapy (pp. 5-44). New York: Plenum.

Ouellette, J . A., \& Wood, W. (1998). Habit and intention in everyday life: The multiple processes by which past behavior predicts future behavior. Psychological Bulletin, 124, 54-74.

Parsons, J . E., \& Bales, R. F. (1955). Family: Socialization and interaction process. Glencoe, IL: Free Press.

Pindyck, R. S., \& Rubenfeld, D. L. (1981). Econometric models and economic forecasts. New York: McGraw-Hill.

Powell, M., \& Ansic, D. (1997). Gender differences in risk behaviour in financial decision-making: An experimental analysis. J ournal of Economic Psychology, 18, 605-628.

Randall, D., \& Gibson, A. (1991). Ethical decision making in the medical profession: An application of the theory of planned behavior. J ournal of Business Ethics, 10, 111-122.

Roberts, T. (1991). Gender and the influence of evaluations in self assessments in achievement settings. Psychological Bulletin, 109, 297-308.

Rosenkrantz, P., Vogel, P., Bee, H., Broverman, I., \& Broverman, D. M. (1968). Sex-rolestereotypes and self-concepts in collegestudents. J ournal of Consulting and Clinical Psychol ogy, 32, 287- 295.

Ross, C. E., \& Wright, M. P. (1998). Women's work, men's work, and the sense of control. Work and Occupations, Thousand Oaks, CA: Sage.

Rotter, G. S., \& Portugal, S. M. (1969). Group and individual effects in problem solving. J ournal of Applied Psychology, 53, 338-341.

Sargent, A. (1981). The androgynous manager. New York: AMACOM.

Sauser, W., \& York, C. (1978). Sex differences in job satisfaction: A reexamination. Personnel Psychology, 31, 537-547. 
Schuler, R. (1975). Sex, organizational level, and outcome importance: Where the differences are. Personnel Psychology, 28, 365-375.

Sheppard, B. H., Hartwick, J ., \& Warshaw, P. R. (1988). The theory of reasoned action: A metaanalysis of past research with recommendations for modifications and future research. J ournal of Consumer Research, 15, 325-343.

Sichel, D. E. (1997). The computer revolution: An economic perspective. Washington, DC: The Brookings Institution.

Skitka, L. J ., \& Maslach, C. (1996). Gender as schematic category: A role construct approach. Social Behavior and Personality, 24, 53-74.

Sparks, P., Guthrie, C. A., \& Shepherd, R. (1997). The Dimensional Structure of the Perceived Behavioral Control Construct. J ournal of Applied Social Psychology, 27, 418-438.

Steffen, T. M., \& Nystrom, P. C. (1988). Problem solving by hospital managers. Health Care Management Review, 13, 25-32.

Stein, A. H., \& Bailey, M. M. (1973). The socialization of achievement orientation in females. Psychological Bulletin, 80, 345-366.

Stockard, J ., Van-de-Kragt, A. J ., \& Dodge, P. J . (1988). Gender roles and behavior in social dilemmas: Are there sex differences in cooperation and in its justification? Social Psychology Quarterly, 51, 154- 163.

Szajna, B., \& Scamell, R. W. (1993). The effects of information system user expectations on their performance and perceptions. MIS Quarterly, 17, 493-516.

Talaga, J . A., \& Beehr, T. A. (1995). Aretheregender differences in predicting retirement decisions? J ournal of Applied Psychology, 80, 16-29.

Tashakkori, A. (1993). Gender, ethnicity, and the structure of self-esteem: An attitude theory approach. J ournal of Social Psychology, 133, 479-488.

Tashakkori, A., \& Thompson, V. D. (1991). Race differences in self-perception and locus of control during adolescence and early adulthood: Methodological implications. Genetic, Social, and General Psychology Monographs, 117, 133- 152.

Taylor, M. C., \& Hall, J . A. (1982). Psychological androgyny: Theories, methods, and conclusions. Psychological Bulletin, 92, 347-366.

Taylor, S., \& Todd, P. A. (1995). Understanding information technology usage: A test of competing models. Information Systems Research, 6, 144-176.

Thoits, P. A. (1987). Gender and marital status differences in control and employment. Monthly Labor Review, 114, 10-18.

Van Roosmalen, E. H., \& McDaniel, S. A. (1992). Adolescent smoking intentions: Gender differences in peer context. Adolescence, 27, 87-105.

Venkatesh, V., \& Davis, F. D. (2000). A theoretical extension of the technology acceptance model: Four longitudinal field studies. Management Science.

Venkatesh, V., \& Morris, M. G. (2000). Why don't men ever stop to ask for directions? Gender, social influence, and their role in technology acceptance and usage behavior. MIS Quarterly.

Venkatesh, V., \& Speier, C. (1999). Computer technology training in the workplace: A longitudinal investigation of the effect of mood. Organizational Behavior and Human Decision Processes, 79, 1-28.

Warshaw, P. R. (1980). A new model for predicting behavioral intentions: An alternativeto Fishbein. J ournal of Marketing Research, 17, 153-172.

Warshaw, P. R., \& Davis, F. D. (1985a). The accuracy of behavioral intention versus behavioral expectation for predicting behavioral goals. J ournal of Psychology, 119, 599-602.

Warshaw, P. R., \& Davis, F. D. (1985b). Disentangling behavioral intention and behavioral expectation. J ournal of Experimental Social Psychology, 21, 213-228. 
Weiner, L. R. (1993). Digital woes: Why we should not depend on software Reading, MA: Addison-Wesley.

Weller, L., Shlomi, A., \& Zimont, G. (1976). Birth order, sex, and occupational interest. J ournal of Vocational Behavior, 8, 45-50.

Williams, J . E., \& Best, D. L. (1982). Measuring sex stereotypes: A thirty-nation study. Beverly Hills: Sage.

Wilson, J . S., Stocking, V. B., \& Goldstein, D. (1994). Gender differences in motivations for course selection: Academically talented students in an intensive summer program. Sex Roles, 31, 349-350.

Received March 2, 1999; published online J uly 27, 2000 